\title{
Isolation, characterization, and multiplexing of novel microsatellite markers for the tropical scalloped spiny lobster (Panulirus homarus)
}

M. Delghandi', S. Goddard' ${ }^{1}$, D.R. Jerry ${ }^{2}$, H.T. Dao ${ }^{2}$, H. Afzal' ${ }^{1}$ and S.S. Al-Jardani ${ }^{3}$

${ }^{1}$ Centre of Excellence in Marine Biotechnology, Sultan Qaboos University, Al-Khoud, Sultanate of Oman

${ }^{2}$ Centre for Sustainable Tropical Fisheries and Aquaculture and College of Marine and Environmental Science, James Cook University, Townsville, Australia

${ }^{3}$ Ministry of Agriculture and Fisheries Wealth, Muscat, Sultanate of Oman

Corresponding author: M. Delghandi

E-mail: mdelghandi@squ.edu.om

Genet. Mol. Res. 14 (4): 19066-19070 (2015)

Received September 11, 2015

Accepted November 18, 2015

Published December 29, 2015

DOI http://dx.doi.org/10.4238/2015.December.29.14

ABSTRACT. Of the various spiny lobster species in the tropical and subtropical Indo-West Pacific region, the tropical scalloped spiny lobster (Panulirus homarus) supports one of the most commercially valuable fishery resources in many coastal African and Asian countries. The last decade has witnessed a serious decline in the wild populations of this species. Knowledge of the genetic basis of spiny lobster population structure is a prerequisite to achieve a sustainable fisheries management for this species. Here, we describe 13 novel polymorphic microsatellite markers developed for $P$. homarus, using a cross-species primer design strategy based on $P$. ornatus Roche 454 shot-gun generated sequencing. Microsatellite polymorphisms were assessed in 96 unrelated $P$. homarus individuals of a natural population, with the number of alleles per locus varying from 2 to 14 , the observed and expected heterozygosity from 
0.00 to 0.78 and from 0.03 to 0.79 , respectively, and with only four loci (Pho-G27, Pho-G32, Pho-G36, and Pho-G58) deviating from HardyWeinberg equilibrium. Genetic linkage disequilibrium analysis between all pairs of the loci showed significant departure from the null hypothesis between loci Pho-G22 - Pho-G30, and Pho-G30 - Pho-G35. The successful cross amplification of these microsatellites highlights the potential of the developed microsatellites for future population genetic research within the different Panulirus species.

Key words: Panulirus homarus; Population studies; 454 sequencing; Microsatellites; Multiplexing

\section{INTRODUCTION}

Spiny lobsters (Palinuridae) are considered as a luxury food and support valuable fisheries, which are of considerable socio-economic importance worldwide. Twenty different species belonging to the genus Panulirus are described, of which 5 are found in the Atlantic region and 15 in the IndoPacific region (Holthuis, 1991). The scalloped spiny lobster, Panulirus homarus, contains three sub-species: P. homarus homarus (Linnaeus, 1758), P. homarus megasculptus (Pesta, 1915), and P. homarus rubellus (Berry, 1974). Of these, Panulirus $h$. homarus is the most widely distributed and is found throughout the Indo-Pacific region with centers of high concentrations in East Africa and Indonesia (Berry, 1974; Pollock, 1993). The other two subspecies, P. h. megasculptus and $P$. h. rubellus, are restricted to the Arabian Sea and southeast coasts of Madagascar and Southern Africa, respectively. Over-harvesting and destructive fishing practices, along with the degradation of the natural habitat from pollution and human activities have led to decline in the wild spiny lobster populations worldwide (FAO, 2012; Folmer et al., 1994). The genetic characteristics of $P$. homarus populations and sometimes of the entire species are relevant to its management. Therefore, the study of population genetic structure, the geographic distribution of genetic variation among and within populations, and the historical and current gene flow is of significant management interest. Genetic markers are imperative for genetic studies of spiny lobsters because they provide information to ensure sustainable fishery management and stock assessment, as well as to produce valuable knowledge for aquaculture of the species. However, at present, few efforts have been initiated to include potentially more powerful genetic markers, such as microsatellites, for population studies of spiny lobsters. Here, we report the isolation and characterization of 13 novel genomic microsatellite loci, which can be used as a tool for understanding the genetic status of different Panulirus species and for the development of rational conservation management plans for these species.

\section{MATERIAL AND METHODS}

Dao et al., 2013 previously conducted a Roche 454 whole-genome sequence run in a closely related species, $P$. ornatus, and subsequently used the sequencing data to isolate 15 assayable microsatellite markers. Given the close taxonomic relationships between $P$. ornatus and the species of interest in this study, the same $P$. ornatus sequence database was mined for perfect di-, tri-, and tetra-nucleotide microsatellite repeats using iQDD (Meglecz et al., 2010) and 
MSATcommander version 0.8.2 (Faircloth, 2008), which incorporates Primer3 software for PCR primer design (parameters: product length $150-400 \mathrm{bp}$; annealing temp $50-63^{\circ} \mathrm{C}$; GC content $20-$ $80 \%$ ). From this data mining, 370 independent sequence regions with microsatellite repeats and their possible primers were identified. Potential loci with primers were subsequently filtered based on distance of primers from the beginning and end of a sequence (>10 bp), distance between primers and motif repeat (>10 bp), and PCR product length $(75-400 \mathrm{bp})$. For this quality check, 40 perfect di-, tri-, and tetra-nucleotide microsatellite repeats were chosen for PCR validation in $P$. homarus. Genomic DNA from 96 unrelated individuals, originated from randomly selected pueruli from a single sampling site in Vietnam, were extracted by cetyltrimethylammonium bromide (CTAB) extraction method (Sambrook and Russell, 2001). Initially, 16 DNA samples were used to check the success of primer cross-species amplification. The amplification was carried out individually in 15- $\mu \mathrm{L}$ reaction volume, containing 10-50 ng genomic DNA, $9 \mu \mathrm{L}$ True Allele premix (Applied Biosystems, Foster City, USA), $1 \mathrm{mM} \mathrm{MgCl}, 0.4 \mu \mathrm{M}$ each unlabeled forward and reverse primer (Metabion; Martinsried, Germany) in a Veriti Thermal Cycler (Applied Biosystems). Thermal cycling conditions were $15 \mathrm{~min}$ at $95^{\circ} \mathrm{C}$, followed by 32 amplification cycles at $94^{\circ} \mathrm{C}$ for $30 \mathrm{~s}, 56^{\circ} \mathrm{C}$ for $90 \mathrm{~s}$, and $72^{\circ} \mathrm{C}$ for $60 \mathrm{~s}$, and then a final extension at $72^{\circ} \mathrm{C}$ for $30 \mathrm{~min}$. Thirteen polymorphic microsatellites were reliably amplified across all 16 individuals examined when evaluated using $2 \%$ high-resolution agarose. For fluorescent detection and multiplexing of the scored loci the forward primers were labeled with dyes PET, NED, VIC or 6-FAM; Applied Biosystems; Table 1). A PIG-tail sequence 5'-GTTTCTT-3' (Brownstein et al., 1996) was used as the reverse primer. Genomic DNA from 96 unrelated $P$. homarus individuals were amplified in 3 multiplexes (Table 1) and screened on a 3130 capillary sequencer (Applied Biosystems) to evaluate the efficiency of amplification and polymorphism of the markers. The amplification was carried out in a $15-\mu \mathrm{L}$ reaction volume containing 10-50 ng template, $9 \mu \mathrm{L}$ True Allele premix, $1 \mathrm{mM} \mathrm{MgCl}$, and adjusted primer concentrations to yield consistent and relatively uniform fluorescence among loci (Table 1 shows primer concentrations at each locus). Thermal cycling conditions were as follows: $12 \mathrm{~min}$ at $95^{\circ} \mathrm{C}$, followed by 32 amplification cycles at $95^{\circ} \mathrm{C}$ for $20 \mathrm{~s}, 58^{\circ} \mathrm{C}$ for $20 \mathrm{~s}$, and $72^{\circ} \mathrm{C}$ for $30 \mathrm{~s}$, and then a final extension at $72^{\circ} \mathrm{C}$ for 30 min. Genotyping was performed using a 3130 Genetic Analyzer (Applied Biosystems). Data were collected automatically and sized with GeneMapper software (Applied Biosystems) using the GeneScan-500-LIZ size standard (Applied Biosystems).

\section{RESULTS AND DISCUSSION}

Out of 40 primer pairs, 13 were both readily scorable and polymorphic (Table 1 ). Statistical calculations were performed using the program Genepop version 3.4 (Raymond and Rousset, 1995). The number of alleles per locus $(A)$, observed heterozygosity $\left(H_{0}\right)$, expected heterozygosity $\left(H_{\mathrm{E}}\right)$, and inbreeding coefficient $\left(F_{\mathrm{IS}}\right)$ were calculated. The number of alleles varied from 2 to 14 per locus and $H_{\mathrm{O}}$ and $H_{\mathrm{E}}$ ranged from 0.00 to 0.78 and from 0.03 to 0.79 , respectively (Table 1). The loci were further tested for conformance to both Hardy-Weinberg equilibrium (HWE) and linkage disequilibrium and significance levels were determined after 100 batches of 5000 interactions each. Four of the loci (Pho-G27, Pho-G32, Pho-G36, and Pho-G58) deviated from HWE after sequential Bonferroni correction (Rice, 1989), probably due to the small sample size, genetic drift and the presence of null alleles. Two of 78 pairwise exact tests rejected genotypic equilibrium between loci (Pho-G22 - Pho-G30 and Pho-G30 - Pho-G35) after sequential Bonferroni correction. In conclusion, the cross species primer design amplification strategy proved to be a cost-effective 
Microsatellite markers for tropical scalloped spiny lobster

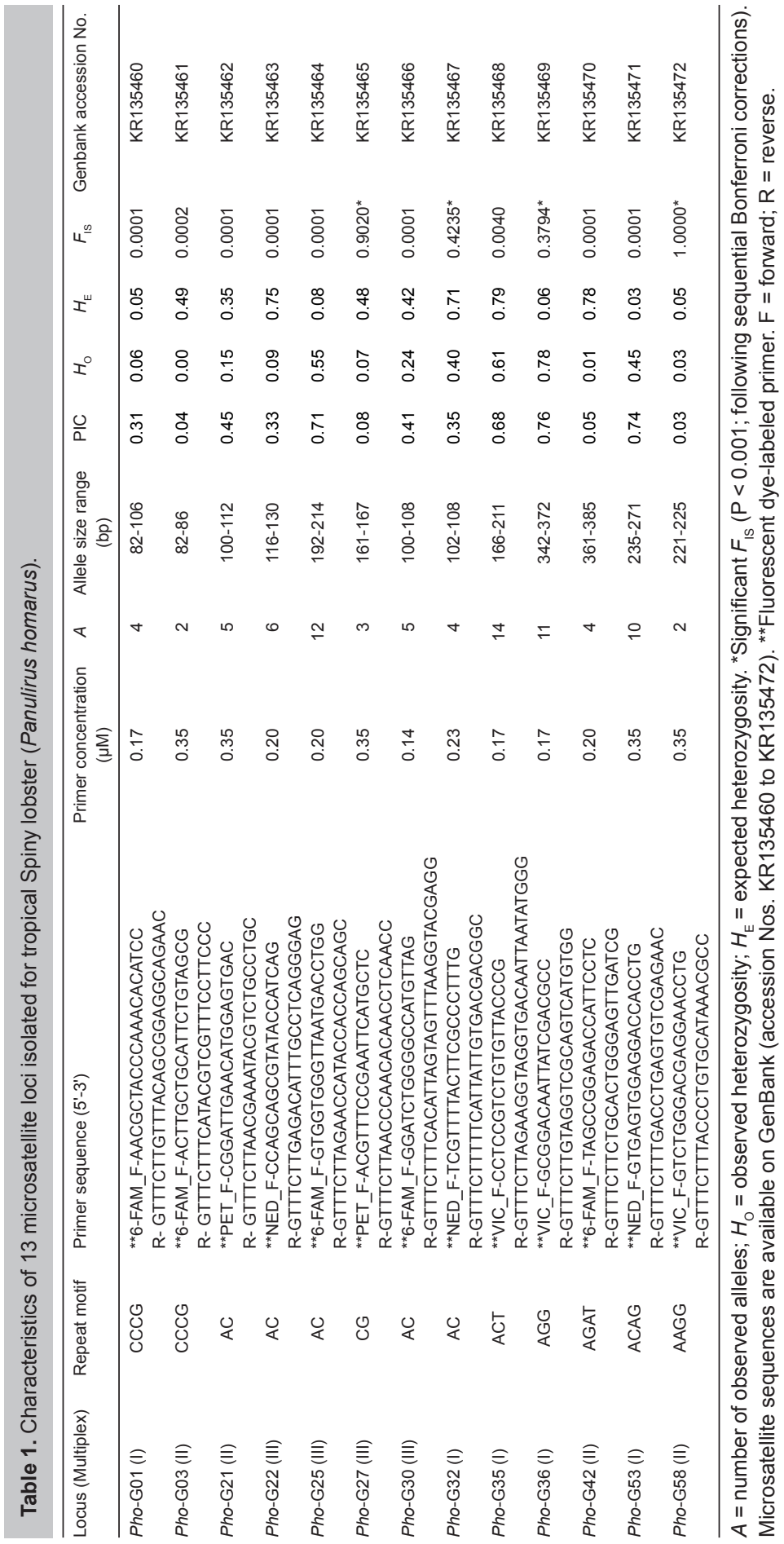


and rapid approach to isolate microsatellite markers in related species. The 13 polymorphic microsatellite loci provide useful tools for studies of population genetics, reproductive ecology, and for constructing linkage maps for the two different Panulirus species studied here.

\section{Conflicts of interest}

The authors declare no conflict of interest.

\section{ACKNOWLEDGMENTS}

Research supported by the Research Council of Oman (TRC) (\#ORG/SQU/EBR/13/027) and by the Deanship of research at the Sultan Qaboos University (\#IG/DVC/CEMB/14/01).

\section{REFERENCES}

Berry PF (1974). A revision of the Panulirus homarus-group of spiny lobsters (Decapoda, Palinuridae). Crustaceana 27: 31-42. Brownstein MJ, Carpten JD and Smith JR (1996). Modulation of non-templated nucleotide addition by Taq DNA polymerase: primer modifications that facilitate genotyping. Biotechniques 20: 1004-1006.

Dao HT, Todd EV and Jerry DR (2013). Characterization of polymorphic microsatellite loci for the spiny lobster Panulirus spp. and their utility to be applied to other Panulirus lobsters. Conser. Genet. Resour. 5: 43-46.

Faircloth BC (2008). MSATCOMMANDER: detection of microsatellite repeat arrays and automated, locus-specific primer design. Mol. Ecol. Resour. 8: 92-94.

FIGIS (2012). Global Capture Production 1950-2010. Food and Agriculture Organization.

Folmer O, Black M, Hoeh W, Lutz R, et al. (1994). DNA primers for amplification of mitochondrial cytochrome c oxidase subunit I from diverse metazoan invertebrates. Mol. Mar. Biol. Biotechnol. 3: 294-299.

Holthuis LB (1991). Marine lobsters of the world. An annotated and illustrated catalogue of species of interest to fisheries known to date. FAO Species Catalogue. FAO Fish. Synopsis 13: 1-292.

Meglecz E, Costedoat C, Dubut V, Gilles A, et al. (2010). QDD: a user-friendly program to select microsatellite markers and design primers from large sequencing projects. Bioinformatics 26: 403-404.

Pollock DE (1993). Speciation in Spiny-Lobsters - Clues to Climatically-Induced Changes in Ocean Circulation Patterns. Bull. Mar. Sci. 53: 937-944.

Raymond M and Rousset F (1995). Genepop (Version 1.2) - Population genetics software for exact tests and Ecumenicism. J. Hered. 86: 248-249.

Sambrook J and Russell DW (2001). Molecular cloning: a laboratory manual. Cold Spring Harbor Laboratory Press, New York. 